\title{
A(s) Guerra(s) dos Meninos: Uma Adaptação, Vários Sentidos ${ }^{1}$
}

\author{
A Guerra dos Meninos: Una Adaptación, Varios Sentidos
}

A Guerra dos Meninos: An Adaptation and a Lot of Senses

\author{
Morgani GUZZO² \\ Rodolfo Rorato LONDERO 3
}

\begin{abstract}
Resumo
Este artigo se propõe a realizar a análise da adaptação do livro-reportagem A Guerra dos Meninos, do jornalista Gilberto Dimenstein (1994), para o documentário homônimo dirigido por Sandra Werneck (1991). A proposta de Dimenstein de investigar e denunciar o número de mortes de meninos de rua em seis capitais brasileiras é mantida pelo documentário. No entanto, ao considerar as especificidades de cada meio, faz-se necessário perceber as estratégias cinematográficas utilizadas como forma de sensibilizar a quem assiste. Muito além de dados jornalísticos, os recursos, como montagem, trilha sonora, narrador em voice over, e as próprias imagens compõem um discurso diferenciado daquele do texto verbal do livro-reportagem, capaz de instigar e, até mesmo, emocionar o espectador.
\end{abstract}

Palavras-chave: Jornalismo; Documentário; Teoria da adaptação; Livro-reportagem; A Guerra dos Meninos.

\section{Resumen}

En este artículo se propone llevar a cabo el análisis de la adaptación del libro-informe $A$ Guerra dos Meninos, escrito por el periodista Gilberto Dimenstein (1994), para el cine documental del mismo nombre dirigido por Sandra Werneck (1991). La propuesta de Dimenstein - investigar y reportar las muertes de niños de la calle en seis capitales brasileñas - es mantenido por el documental. Sin embargo, al considerar las características específicas de cada medio, es necesario entender las estrategias de la película para sensibilizar al espectador. Más allá de los datos periodísticos, los recursos tales como montaje, efectos de sonidos, narrador en voz off y, por supuesto, las imágenes, conforman un discurso distinto que el texto verbal del libro, capaz de instigar e incluso emocionar al espectador.

Palabras clave: Periodismo; Cine documental; Teoría de la adaptación; A Guerra dos Meninos.

1 Artigo apresentado à oitava edição da Revista Ação Midiática - Estudos em Comunicação, Sociedade e Cultura, publicação ligada ao Programa de Pós-Graduação em Comunicação, da Universidade Federal do Paraná.

2 Mestranda em Letras no Programa de Pós-Graduação em Letras da Universidade Estadual do Centro-Oeste (Unicentro-PR), bolsista CAPES, formada em Comunicação Social com habilitação em Jornalismo pela mesma Universidade. E-mail: morganiguzzo@gmail.com

3 Doutor em Estudos Literários pela Universidade Federal de Santa Maria, Mestre em Estudos Literários e Bacharel em Comunicação Social - Habilitação em Jornalismo, ambos pela Universidade Federal de Mato Grosso do Sul. E-mail: rodolfolondero@bol.com.br 


\title{
açãô midiática \\ № 8 । Ano 2014
}

Universidade Federal do Paraná | Programa de Pós-Graduação em Comunicação

\begin{abstract}
This paper intends to perform the analysis of the adaptation of the book-report A Guerra dos Meninos, by Gilberto Dimenstein (1994), for the eponymous documentary directed by Sandra Werneck (1991). The Dimenstein's purpose - investigate and report the deaths of street children in six Brazilian capitals - is maintained by the documentary. However, when considering the specificities of each media, it is necessary to understand the cinematic strategies used as a way to sensitize the viewer. Beyond journalistic data, resources like assembly, soundtrack, voice over and the images make up a distinct discourse of verbal text of the book, capable of instigating and even thrill the viewer.
\end{abstract}

Keywords: Journalism; Documentary; Adaptation theory; A Guerra dos Meninos

\section{Introdução}

Diferente da efemeridade da maioria das produções jornalísticas periódicas e fugindo da abordagem limitada de causa e efeito de um acontecimento, a obra que une literatura e jornalismo investigativo transpõe a superficialidade e a uniformidade do conteúdo jornalístico factual. Por meio do livro-reportagem, o jornalista conquista uma liberdade maior no campo da escrita, produz um texto mais artístico e, ainda, alcança o fator da permanência, possível devido ao aprofundamento do fato e da quantidade de enfoques que consegue abranger.

A Guerra dos Meninos (1994) é um exemplo de denúncia social publicado em livro. Em pouco mais de cem páginas o autor Gilberto Dimenstein faz um retrato sobre o assassinato de crianças e adolescentes por grupos de extermínio em seis das principais capitais brasileiras. Foram mais de trezentas entrevistas que, unidas às informações estatísticas contidas em documentos e pesquisas, fazem do livro um trabalho jornalístico de mérito. O aprofundamento da notícia, por meio da contextualização e da interpretação dos fatos e das fontes, é essencial para que haja a compreensão deste problema superficialmente visto como de segurança pública - no qual a violência provocada por e contra meninos de rua é apenas a ponta do iceberg.

Outro exemplo de um trabalho de fôlego do jornalismo é o documentário. Segundo Cunha (1990), o documentário tem um compromisso com a verdade e busca documentar um acontecimento com fidelidade, ao mesmo tempo em que possibilita uma reflexão sobre os fatos. "O importante é que um bom documentário não deve nunca concluir, fechar questões sobre o tema proposto. $\mathrm{O}$ documentário deve ser tomado conforme seus ângulos. O julgamento de seu enfoque é feito pelo telespectador. Fazê-lo refletir é o que importa" (CUNHA, 1990, p. 111).

O documentário A Guerra dos Meninos (1991) de Sandra Werneck, baseado no livroreportagem de Dimenstein, tem, além do nome, o mesmo objetivo: trazer à luz um problema social brasileiro, dando voz às crianças e aos movimentos de defesa dos direitos dos menores e buscando a sensibilização do poder público e da sociedade. 
Tanto o filme quanto o livro abordam o número alarmante de menores mortos por grupos de extermínio como consequência de problemas sociais mais profundos: a pobreza e a desigualdade social. A situação detectada no momento em que a investigação foi realizada - no final da década de 1980 e começo da de 1990 - demonstra que o fato de grande parte da população brasileira viver em condições miseráveis resulta em consequências graves para a sociedade, sendo uma delas a desestruturação familiar. Os menores, além de precisarem trabalhar para ajudar no sustento da família, precisam lidar com a fome, a falta de escolas e com os problemas enfrentados em casa, como o alcoolismo e a violência. O testemunho de comerciantes, policiais, membros de instituições de proteção ao menor, crianças de rua, menores infratores, jornalistas, entre outros, compõem a estrutura de ambos os produtos culturais - livro e filme. No entanto, com base na teoria da adaptação, veremos que a diferença entre os meios traz a necessidade de modificações estruturais e, consequentemente, produzem efeitos de sentido distintos.

Pela compreensão das especificidades de cada um dos meios, é possível analisar quais recursos foram utilizados por Dimenstein (1994) e Werneck (1991) na construção da narrativa de denúncia social sobre a atuação dos grupos de extermínio - que é justificada pelos comerciantes e policiais e condenada por juízes, jornalistas e membros de associações de defesa do menor -, enquanto traz à tona problemas sociais profundos que vão desde a falta de oportunidades de sobrevivência digna dos menores até a precariedade da segurança pública nos grandes centros.

\section{A voz dos mortos: o documentário e o processo de adaptação}

A apropriação do título do livro-reportagem de Gilberto Dimenstein (1990) para o documentário de Sandra Werneck (1991) já denota, segundo Diniz (2005), que essa produção pode ser considerada uma adaptação, "isto é, a narrativa de uma história preexistente através dos recursos do cinema, (...) a tradução intersemiótica, de uma obra concebida no sistema verbal para outro sistema de signos, o cinemático" (DINIZ, 2005, p. 34).

O enfoque do livro-reportagem A Guerra dos Meninos (1994) e do documentário homônimo é a mesma: o extermínio de crianças e adolescentes - grande parte em situação de rua - por grupos de extermínio nas principais capitais brasileiras. Com exceção do número de entrevistas e da estrutura básica que diferencia os meios, o resultado é basicamente o mesmo: a denúncia da "ciranda viciada"4 gerada por um problema social e econômico brasileiro.

As adaptações geralmente são estudadas a partir da produção de filmes baseados em romances. Na maioria das abordagens sobre adaptação, coloca-se a literatura - sendo a obra original - como obra superior em uma hierarquia de valores artísticos, enquanto o valor da

4 "Ciranda viciada" é o título do primeiro capítulo do livro de Gilberto Dimenstein (DIMENSTEIN, 1994, p. 15). 
adaptação pelo cinema é considerado de acordo com a sua "fidelidade" com relação à obra original.

A análise de adaptações é realizada em diversas áreas do conhecimento - filosofia, linguística, comunicação, entre outras - e, há algumas décadas, teorias próprias têm surgido como forma de compreender esse processo que pode ser entendido como tradução, ou seja, como crítica ou "leitura" do romance original, desprendendo-se do caráter comparativo de "fidelidade" com relação à literatura e respeitando os limites de cada meio.

Segundo Stam (2006), há movimentos e tendências teóricas que rebaixam o texto literário de sua posição de autoridade opressiva, apontando para uma possível reconceitualização da adaptação. Um exemplo é o campo interdisciplinar de "estudos culturais", que se mostra mais interessado em explorar as relações horizontais entre mídias fronteiriças do que em estabelecer hierarquias "verticais" de valor.

Sob uma perspectiva cultural, a adaptação faz parte de um espectro de produções culturais niveladas e, de forma inédita, igualitárias. Dentro de um mundo extenso e inclusivo de imagens e simulações, a adaptação se torna apenas um outro texto, fazendo parte de um amplo contínuo discursivo (STAM, 2006, p. 24).

Stam (2006) explora outras formas de análise da adaptação, tais como a narratologia - teoria de forte tendência nos estudos de cinema desde os anos 1970, na qual as narrativas de ficção e as de não ficção são estudadas por meio de suas estruturas e elementos -, a teoria da recepção - que também reafirma a adaptação enquanto forma, teoria que evidencia que o romance, texto polifônico e "dialógico", torna-se suscetível a interpretações múltiplas, incluindo a forma de adaptações, como leituras ou interpretações (STAM, 2006) -, e a teoria performativa - que concebe que, assim como a proferição literária cria situações ao invés de só imitar algum estado das coisas preexistentes, a adaptação cinematográfica produz uma nova situação áudio-visual-verbal, moldando novos mundos ao invés de simplesmente retratar/ trair mundos antigos (STAM, 2006). No livro-reportagem, é preciso reconstruir cenas a partir de depoimentos e entrevistas: tudo é transmitido por meio da descrição dos fatos feita pelos próprios entrevistados. Já no documentário, há a possibilidade de recriação dos acontecimentos por meio da imagem. Neste, as simulações de violência contra os menores complementam os depoimentos, servem como ilustração do que está sendo dito.

Para compor uma análise de mutações de formas entre mídias, tem-se à disposição um número considerável de termos e cada um deles - adaptação como tradução, performance, recriação, reciclagem, leitura, hipertexto, entre outros - diz respeito a uma face diferente da adaptação. Segundo Stam (2006), a adaptação enquanto "leitura" da fonte do romance, por exemplo, sugere que é possível gerar um número infinito de "leituras adaptação" inevitavelmente 
parciais e com interesses específicos. Já a "metáfora da tradução" sugere um esforço de transposição intersemiótica, com inevitáveis perdas e ganhos típicos de qualquer tradução.

Segundo Diniz (2005), a análise de adaptações deve ocorrer partindo da concepção da intertextualidade e não da fidelidade. "É importante, pois, que os envolvidos em cinema e em literatura abandonem a abordagem da fidelidade em favor da evocação mais produtiva da intertextualidade sem queixas pela perda do que é peculiar à literatura" (DINIZ, 2005, p. 35).

Seguindo a teoria de McFarlane, a adaptação pode ser arrojada e inteligente, mas deve, ao mesmo tempo, estar ligada ao texto anterior, sendo avaliada como filme, como produto de determinado sistema industrial ou de determinado gênero (MCFARLANE apud DINIZ, 2005, p. 34). Segundo Diniz (2005), com base nesse ponto de vista, "o texto anterior torna-se apenas um aspecto de intertextualidade do filme, de maior ou menor importância, dependendo do conhecimento que o espectador tenha daquele" (DINIZ, 2005, p. 34), e nem o texto literário, nem o autor possuem "autoridade do controle legal" sobre as ramificações intertextuais.

A análise da adaptação de $A$ Guerra dos Meninos tem como pressuposto as características específicas de cada um dos suportes, evidenciando o processo de produção e delineando, assim, as releituras dos fatos jornalísticos realizadas na adaptação. O documentário A Guerra dos Meninos (1991), baseado no livro-reportagem homônimo de Dimenstein (1994), traz, evidentemente, fatos jornalísticos. De acordo com Bernard (2008), diferente do cinema de ficção, o documentarista não lida com um mundo "imaginado", ele utiliza de aspectos cinematográficos para conduzir os telespectadores a descobertas de novos mundos e experiências por meio da apresentação factual de acontecimentos que, por sua vez, são retratados utilizando-se de imagens e de componentes reais.

Apesar de prezar pelo verossímil, o documentário deve ser entendido como uma representação e nunca como uma janela para a "realidade". Conforme Nichols (2005), "o cineasta sempre foi testemunha participante e ativo fabricante de significados, sempre foi muito mais um produtor de discurso cinemático do que um repórter neutro ou onisciente da verdadeira realidade das coisas" (NICHOLS, 2005, p. 49).

Há ainda uma polêmica inserida nas discussões sobre documentários, segundo Tavares (2005): a dualidade ficção ${ }^{5}$ versus realidade. As discussões circulam entre questões como: a câmera modifica ou não o mundo que está capturando? Ocorre a descaracterização do documentário com a utilização de encenação ou outros recursos dramáticos? A montagem já não insere essa produção no viés da ficção pela interferência do autor? Outros pontos sobre essa dualidade são levantados nos estudos sobre documentários, tais como o conceito de representação, a diversidade de abordagens sobre o que é ou não ficção, entre outras.

5 Aqui, compreenderemos o conceito "ficção" no sentido lato de imaginação, invenção, criação. 
Para compreender as especificidades do documentário A Guerra dos Meninos (1991), parte-se de uma abordagem prática do objeto enquanto "cinema da asserção pressuposta". Esse conceito é teorizado por Carroll (2005), inspirado em Paul Grice, e pressupõe que um artista ou autor comunica-se com sua audiência por meio da indicação de como pretende que esse público responda a seu texto, ou seja, o emissor precisa comunicar à audiência que sua intenção é que o texto seja lido como ficção, para que o público responda a ele adotando uma postura ficcional.

Baseado na "asserção pressuposta", não nos debruçaremos sobre a definição do que seja ou não documentário - os elementos levantados pelos autores vão desde a questão ética e política até chegar à sua forma e conteúdo -, aceitando, portanto, que a caracterização de um documentário depende da intenção do emissor. No caso do livro-reportagem (1994), a intenção do autor é apresentada no prefácio; no documentário (1991), a abertura apresenta a informação de que a produção é baseada no livro de Gilberto Dimenstein, demonstrando o caráter jornalístico do produto.

Para fins didáticos, Ramos (2008) define documentário como uma "narrativa com imagens-câmera que estabelece asserções sobre o mundo, na medida em que haja um espectador que receba essa narrativa como asserção sobre o mundo" (RAMOS, 2008, p. 22), ou seja, o documentário conta uma história, permite a visualização de questões que necessitam de atenção, coloca o telespectador diante de problemáticas diversas e, ao mesmo tempo, pode sugerir soluções possíveis para as questões abordadas. Para Nichols (2005), o documentário e o filme de ficção, apesar de suas diferenças, podem utilizar elementos que se assemelham, tais como, de um lado, a roteirização, a encenação, a reconstituição, o ensaio e a interpretação; e, de outro, as filmagens externas, as câmeras portáteis, a improvisação e as imagens de arquivo etc.

Além da narrativa, as imagens tornam o documentário singular com relação ao livro-reportagem. Na linguagem cinematográfica, as imagens ordenadas e postas em movimento se condensam em uma narrativa que, unida aos recursos sonoros, possibilita inúmeras sensações. No caso do documentário A Guerra dos Meninos (1991), Werneck intercala depoimentos de meninos de rua, comerciantes, policiais, defensores dos direitos da criança, entre outros, une os depoimentos a imagens e a fotografias de crianças mortas ou violentadas, acrescenta simulações de violência, trilha sonora e um narrador, com o objetivo de sensibilizar, ao mesmo tempo em que denuncia questões já apresentadas no livro-reportagem.

Com relação ao processo adaptativo, Giannetti (1990) demonstra que a construção de uma narrativa fílmica passa por um intenso processo estético de criação: "filmes sintetizam vários sistemas de linguagens simultaneamente, literalmente bombardeando o espectador com centenas de ideias simbólicas e emoções ao mesmo tempo, algumas explicitamente, outras 
subliminarmente" (GIANNETTI, 1990, p. 408, tradução nossa). Essa construção simultânea de sistemas de linguagens possibilita a sensibilização do espectador, ao mesmo tempo em que funciona para que o discurso na tela atinja verossimilhança.

A análise do documentário A Guerra dos Meninos (1991) considera quatro características principais: a montagem dos depoimentos intercalados; as imagens que compõem a narrativa; a trilha sonora; e o discurso do narrador. Composta por essas características, a adaptação produz efeitos de sentido diferentes daqueles desencadeados pelo discurso pretensamente objetivo e imparcial do livro de Dimenstein (1994).

Segundo Nichols (2005), há, na história do documentário, quatro principais estilos. Partindo dessa abordagem, o "modelo clássico", ou o "estilo direto da tradição greirsoniana", foi a primeira forma acabada de documentário e tinha como principal característica a utilização de uma narração "fora-de-campo" ou "voice over". O sucessor deste é o chamado cinema direto $^{7}$, que "prometia um aumento do 'efeito verdade' graças à objetividade, ao imediatismo e à impressão de capturar fielmente acontecimentos ocorridos na vida cotidiana" (NICHOLS, 2005, p. 48). A partir dos anos 1970, Nichols identifica um terceiro estilo, que incorpora o discurso direto por meio da utilização de entrevistas. "Às vezes profundamente reveladores, às vezes fragmentados e incompletos, esses filmes forneceram o modelo para o documentário contemporâneo" (NICHOLS, 2005, p. 49). Para Ramos (2008), a utilização de depoimentos nos documentários começou na década de 1960, em uma estilística que destacava o diálogo como recurso de exposição dos argumentos. Nesse tipo de produção evidencia-se a valorização do "eu", aquele que fala em primeira pessoa, e estabelece relações e afirmações tidas como verdadeiras sobre a sua própria vida. O quarto e último estilo é caracterizado como "autorreflexivo" e mistura passagens observacionais a entrevistas, a voz sobreposta do diretor ou do narrador a intertítulos, deixando explícito que o documentário é somente uma representação da realidade (NICHOLS, 2005). Este é o modelo no qual se encaixa o documentário A Guerra dos Meninos (1991).

Segundo Ramos, aquele que guia o documentário não é mais somente o narrador (voice over), mas as várias vozes compostas.

A voz do saber, em sua nova forma, perde a exclusividade da modalidade over. Ainda temos a voz over, mas os enunciados assertivos são assumidos por entrevistas, depoimentos de especialistas, diálogos, filmes de arquivo (flexionados para enunciar as asserções de que a narrativa necessita). O documentário, portanto, se caracteriza como narrativa que possui vozes diversas que falam do mundo, ou de si (RAMOS, 2008, p. 24).

6 Tradução livre de: "movies synthesize many languages systems simultaneously, bombarding the spectator with literally hundreds of symbolic ideas and emotions at the same time, some of them overt, others subliminal" (GIANNETI, 1990, p. 408).

7 Cinéma verité no original (NICHOLS, 2005, p. 48). Segundo Tavares (2005), esse modelo surge de uma postura crítica em relação à encenação característica do modelo clássico de Greirson e elegendo a reflexividade como estratégia que deveria ser assumida pelos documentaristas. Nesse estilo, a câmera procura capturar o cotidiano sem interferência. 


\section{açã() midiática \\ № 8 I Ano 2014

Para Tavares (2005), a inserção de entrevistas ao invés da utilização do off - ou over como eixo narrativo possibilita também uma liberdade autoral.

[...] uma das colocações feitas em relação aos produtos audiovisuais que se autodenominam "documentários" é justamente a liberdade de autoria. Ao contrário do modelo consagrado do vídeo-reportagem, que mantém iconicamente a presença do repórter - em um recurso estilístico que diariamente a TV reitera, mantendo, também, o off, como eixo do discurso narrativo apresentado na tela -, o documentário, quase maciçamente, não apresenta seu realizador ou equipe de realização (TAVARES, 2005, p. 4).

Segundo Field, "um romance geralmente lida com a vida interior de alguém", com "pensamentos, sentimentos e memórias do personagem que ocorrem dentro do cenário mental da ação dramática" (FIELD, 2001, p. 174). O livro-reportagem, utilizando dos recursos literários, também passa a lidar com a "vida interior" dos entrevistados e a maneira de transpor essa linguagem para o documentário é trazer o próprio entrevistado para dar seu depoimento diante da câmera.

Muitos dos entrevistados no documentário A Guerra dos Meninos fazem parte dos mais de trezentos indivíduos que Dimenstein entrevistou para seu livro. São familiares de meninos assassinados, membros de instituições de defesa do direito da criança e do adolescente, policiais, jornalistas, entre outros. No entanto, essa semelhança apenas pode ser percebida no caso de o espectador ter lido o livro de Dimenstein, uma vez que muitos entrevistados, principalmente os familiares das vítimas, as crianças e alguns funcionários do IML, polícia ou comércio que atuam como coadjuvantes na narrativa, não têm sua identidade revelada no documentário.

A maneira de apresentação do entrevistado acontece por meio da inserção de caracteres com o nome do indivíduo e profissão ou por meio da voice over. No livro-reportagem, além da descrição, alguns dos entrevistados aparecem em fotografias, facilitando a identificação.

Um exemplo de entrevistados que não são identificados pelo documentário, mas que estão presentes nas duas narrativas, é a mãe de dois jovens assassinados pela polícia como "queima de arquivo". No produto cinematográfico, a mãe aparece abatida, com os olhos cheios d'água, contando o que acontecera a seus filhos. A câmera também focaliza o movimento das mãos, em alguns momentos, demonstrando a emoção da entrevistada. Esses recursos sensibilizam o espectador. Já no livro-reportagem, a mesma mãe - identificada por nós pela semelhança da história contada - é Maria Helena Mendes, moradora de uma casa em um cortiço de Duque de Caxias. A sensibilização do leitor ocorre pela escrita: descrição da cena, das ações e das emoções. 


\title{
açãô) midiática \\ Estudos em Comunicação, Sociedade e Cultura \\ № 8 I Ano 2014 \\ Universidade Federal do Paraná | Programa de Pós-Graduação em Comunicação
}

\begin{abstract}
Maria Helena Mendes abriu a porta, assustada. Os "policiais" diziam que precisavam levar seus dois filhos Fernando e Aldenir. Iriam para a Delegacia de Menores. Foram levados à força. A mãe ficou desesperada, chamou os vizinhos e foi à delegacia, depois que seus filhos partiram. Não estavam lá, como temia. Passou a noite procurando os dois. Não encontrou. Logo de manhã, uma vizinha, esbaforida, foi dar a má notícia. Viu os dois corpos próximos à casa. Estavam inteiramente queimados e cravejados de balas. Eram eles (DIMENSTEIN, 1994, p. 54).
\end{abstract}

Por usar alguns dos personagens já entrevistados pelo livro, o argumento do documentário mostra-se "fiel" ao livro-reportagem, caso fôssemos analisá-lo pela questão da "fidelidade" da adaptação. A utilização de muitas testemunhas que Dimenstein (1994) entrevistou é uma maneira de corroborar a validade dos relatos.

Apesar das aproximações, as características próprias do documentário forçam a seleção das fontes mais importantes, a montagem dos depoimentos e a utilização de recursos audiovisuais, visando atender aos objetivos pretendidos. Portanto, a adaptação não necessita da rigorosidade jornalística do livro-reportagem.

O material original é uma fonte. O que você faz com ele para moldá-lo num roteiro é por sua conta. Você pode ter que acrescentar personagens, cenas, incidentes e eventos. Não copie simplesmente um romance para um roteiro; faça-o visual, uma história contada em imagens (FIELD, 2001, p. 176).

Os depoimentos do documentário possibilitam reforçar a situação que as crianças vivem. A presença das próprias crianças na tela relatando suas histórias funciona como prova testemunhal da violência e aumenta o impacto causado pelo documentário. No entanto, a edição dessas entrevistas é realizada de uma maneira característica: antes de qualquer depoimento de menores, há um adulto - policial, psicólogo, defensor dos direitos da criança, juiz, comerciante, entre outros - relatando algum fato - seja falando da violência contra os menores ou reclamando das infrações que essas crianças cometem, os adultos "apresentam" o argumento, como se fossem responsáveis também pela criança que aparece depois como justificativa ou comprovação do que o adulto falara.

Além desse procedimento na organização dos depoimentos, outros aspectos podem ser apontados na forma cinematográfica de contar as histórias dos meninos. A composição das imagens - fotografias, cenas do cotidiano e encenações - caracterizam o apelo à sensibilização do espectador no documentário. A câmera flagra crianças de rua cheirando cola ou vendendo produtos no semáforo; as fotos de Paula Simas ou de arquivos de jornais mostram meninos encapuzados, carregando armas, ou mortos nas ruas da cidade; as encenações ilustram a atuação da polícia, a violência com os meninos, os assaltos praticados pelos meninos de rua, entre outros. 
Segundo Tavares (2005), a preocupação com o grau de verdade dos documentários passa pelo viés da encenação, uma vez que sua presença gera uma polêmica sobre a descaracterização ou não do produto. No entanto, para Ramos (2005), a encenação e o cenário compõem a tradição documentária. "Na encenação, o homogeneidade espacial in/off pode ou não ser plena, o que a caracteriza é o fato de a ação ser fortemente esvaziada de sua carga de espontaneidade" (RAMOS, 2005, p. 160).

Outro recurso cinematográfico utilizado no documentário é a trilha sonora. Segundo Gianetti (1990), os sons no cinema funcionam como meio de incitar emoções. No caso de $A$ Guerra dos meninos, há apenas a utilização de uma música original, composta por David Tyger, que acompanha toda a narrativa, começando com os créditos. "Começando com os créditos de abertura, a música pode servir como uma espécie de proposta que sugere o humor ou espírito do filme como um todo"8 (GIANNETTI, 1990, p. 222, tradução nossa). Essa música, conforme diz Gianetti, compõe o tom de todo o documentário. No entanto, há momentos específicos que divergem da sensação causada pela música: em alguns, dependendo da cena ou do depoimento, é possível despertar a sensibilidade, a compaixão e a tristeza, enquanto em outros, desperta o suspense e o medo. "Com ou sem letra, a música pode ser mais específica quando justaposta com as imagens. Na verdade, muitos músicos têm reclamado que as imagens tendem a roubar da música a sua ambiguidade ancorando tons musicais a específicas ideias e emoções"9 (GIANNETTI, 1990, p. 220-221, tradução nossa).

Relacionada com as imagens, a trilha sonora funciona como mais uma maneira de produzir sensações no espectador. Além da música que acompanha toda a narrativa do produto cinematográfico, a utilização do abre áudio, do silêncio e de outros sons funcionam como quebras na narrativa, produzindo outros efeitos de sentido.

Outro exemplo de quebra na narrativa é a inserção da música "Manoel”, de Fábio Fonseca e Ana Serejo, interpretada por Ed Motta \& Conexão Japeri, aos 13 minutos e 40 segundos. A música é coreografada por meninos de rua e a letra remete à vida dura do povo brasileiro. Além da quebra da narrativa, a inserção das imagens dos meninos dançando essa música na rua também coloca a queixa das dificuldades da população brasileira - trechos da música: "se eu fosse americano minha vida não seria assim" ou "se eu fosse um político minha vida não seria assim" - na voz dos meninos de rua.

Tanto no livro-reportagem quanto no documentário, os dados de pesquisas e de documentos estão em todo momento legitimando os relatos das testemunhas.

8 Tradução livre de: "Beginning with the opening credits, music can serve as a kind of overture to suggest the mood or spirit of the film as a whore" (GIANNETTI, 1990, p. 220-221).

9 Tradução livre de: "With or without lyrics, music can be more specific when juxtaposed with film images. In fact, many musicians have complained that images tent to rob music of ambiguity by anchoring musical tones to specific ideas and emotions"(GIANNETTI, 1990, p. 220-221). 


\section{ação midiática \\ Estudos em Comunicação, Sociedade e Cultura \\ № 8 I Ano 2014 \\ Universidade Federal do Paraná | Programa de Pós-Graduação em Comunicação}

Em Pernambuco os grupos de extermínio patrocinados ou amparados por policiais são ainda mais ousados do que os do Rio de Janeiro. Lá, segundo trabalho do Ibase, $57 \%$ dos homicídios dolosos contra crianças são praticados por grupos de extermínio (DIMENSTEIN, 1994, p. 44).

No documentário, esses dados são apresentados de duas maneiras: pela inserção de dados em texto, possibilitando uma quebra da sequência de depoimentos - o texto em cor branca aparece em um fundo preto, acompanhado pela principal trilha sonora do documentário; e por meio do narrador. $\mathrm{O}$ discurso do narrador, no entanto, é o principal aspecto a ser levado em consideração nessa análise. Aquele que narra o documentário é responsável por guiar o espectador durante a narrativa. É ele que dá o principal efeito que sensibiliza aquele que assiste à A Guerra dos Meninos (1991). Assim como no livro-reportagem, os recursos utilizados na narrativa do documentário instigam os sentimentos. Já nos primeiros minutos, quando fotografias de meninos mortos são mostradas, como o depoimento de um trabalhador de rabecão, é possível perceber qual é o tom da voice over e o efeito de sentido que provoca.

É uma triste ironia, quase uma brincadeira macabra. O garoto que passou a vida sem pais ganha um pai só depois que morre. Crianças que ninguém procura, crianças que ninguém quer achar. Sobras de gente.

É pela linguagem do narrador, desde o início do filme, e da montagem da narrativa que podemos definir os objetivos a que se propõe o documentário. Segundo Eisenstein (2002), diferente da representação, que obriga o espectador a criar, a montagem tem o "poder de estímulo criativo interior do espectador que distingue uma obra emocionalmente empolgante de outra que não vai além da apresentação da informação ou do registro do acontecimento" (EISENSTEIN, 2002, p. 30-31). Além disso, a montagem tem a força de incluir no processo criativo a razão e o sentimento do espectador.

\footnotetext{
O espectador é compelido a passar pela mesma estrada criativa trilhada pelo autor para criar a imagem. $\mathrm{O}$ espectador não apenas vê os elementos representados na obra terminada, mas também experimenta o processo dinâmico do surgimento e reunião da imagem, exatamente como foi experimentado pelo autor. E este é, obviamente, o maior grau possível de aproximação do objetivo de transmitir visualmente as percepções e intenções do autor em toda a sua plenitude (EISENSTEIN, 2002, p. 29).
}

Dessa forma, a montagem de A Guerra dos Meninos (1991), junto aos elementos cinematográficos já apresentados, faz com que o produto se caracterize como uma "obra emocionalmente empolgante", além de criar efeitos de sentido diferentes daqueles provocados pela narrativa do jornalista no livro-reportagem. 


\section{açãô midiática \\ № 8 I Ano 2014}

\section{Outros sentidos, algumas considerações}

A linguagem jornalística, enriquecida pelos recursos da literatura, é a forma. A investigação jornalística, a apuração rigorosa e a denúncia do fato é o conteúdo. O livro-reportagem A Guerra dos Meninos (1994) é a voz dos menores assassinados por uma sociedade que, sofrendo, não vê outra forma de solucionar seus problemas que não simplesmente os exterminando.

Com o mesmo tema, mesmo enfoque e muitas das mesmas fontes, o documentário homônimo utiliza recursos cinematográficos como montagem, trilha sonora, encenação e voz over na construção de uma narrativa impactante, baseada no trabalho jornalístico de Dimenstein. Os sentidos provocados com base na abordagem do mesmo tema são variantes. No entanto, isso se dá não só pelo processo adaptativo e pela subjetividade impregnada na construção de qualquer texto, mas, principalmente, pela mudança no canal comunicativo.

As diferenças entre os meios de produção jornalística e os de produção cinematográfica são importantes para a análise de como os acontecimentos são retratados. Com relação à adaptação cinematográfica de $A$ Guerra dos Meninos, não se trata de analisar a fidelidade de um produto ao outro, mas de abordá-lo como tradução, encontrando nos recursos característicos de cada um dos meios os fatores convergentes e os divergentes que foram utilizados para a denúncia do caso com valor humano, que afloraram a sensibilidade do leitor e espectador. Apesar de ser uma adaptação, o documentário assume uma postura um tanto diferente do proposto no livro-reportagem: oferece ao espectador uma leitura do problema social brasileiro, utilizando o depoimento das próprias crianças, as fotografias e as imagens de meninos mortos, a trilha sonora e a encenação como instrumento de representação da realidade valendo-se do apelo emocional.

Portanto, o que se verifica na análise da adaptação de A Guerra dos Meninos é a mudança de sentido ocorrida. Enquanto Dimenstein (1994) busca a construção da narrativa do livro de uma forma jornalística, mais racional, o documentário faz um apelo ao lado emocional do receptor. Enquanto o livro-reportagem trata-se de uma narrativa argumentativa, o documentário, por meio das imagens e da narração - texto com linguagem literária e utilização cuidadosa do tom de voz e do ritmo da leitura -, produziu um efeito mais sensibilizador. Ao mesmo tempo, o produto cinematográfico pode ser visto como um produtor de efeitos de sentido ideológicos, levando em conta a clara tentativa de chamar a atenção para os problemas sociais no Brasil, por meio das denúncias.

Independente de qual de $A(s)$ Guerra(s) dos Meninos seja lido/assistido, sabe-se que o objetivo maior é que a voz dos meninos de rua seja ouvida e não mais calada a tiros e torturas físicas. O papel social de ambos os produtos foi cumprido, escancarando na tela ou nas páginas do livro uma realidade brasileira ignorada. 


\section{ação midiática \\ Estudos em Comunicação, Sociedade e Cultura \\ № 8 I Ano 2014}

\section{Referências}

A GUERRA DOS MENINOS. Direção: Sandra Werneck. Produção: X. Cineluz, 1991. 1 DVD (51min36), som, color, $16 \mathrm{~mm}$.

BERNARD, Sheila Curran. Documentário: técnicas para uma produção de alto impacto. Rio de Janeiro: Elsevier, 2008.

CARROLL, Noël. Ficção, não ficção e o cinema da asserção pressuposta: uma análise conceitual. In: RAMOS, Fernão Pessoa (Org.). Teoria contemporânea do cinema, v. II. São Paulo: Senac São Paulo, 2005.

CUNHA, Albertino Aor da. Telejornalismo. São Paulo: Atlas, 1990.

DIMENSTEIN, Gilberto. A guerra dos meninos. 9. ed. São Paulo: Brasiliense, 1994.

DINIZ, Thaïs Flores Nogueira. Literatura e cinema: tradução, hipertextualidade, reciclagem. Belo Horizonte: Faculdade de Letras da UFMG, 2005.

EISENSTEIN, Sergei. O sentido do filme. Trad. Teresa Ottoni. Rio de Janeiro: Jorge Zahar, 2002.

FIELD, Syd. Manual do roteiro: os fundamentos do texto cinematográfico. Rio de Janeiro: Objetiva, 2001.

GIANNETTI, Louis D. Understanding Movies. 5. ed. New Jersey: Prentice-Hall, Inc. 1990.

NICHOLS, Bill. A voz do documentário. In: RAMOS, Fernão Pessoa (Org.). Teoria contemporânea do cinema, v. II. São Paulo: Senac São Paulo, 2005.

Introdução ao documentário. Campinas, SP: Papirus, 2005.

RAMOS, Fernão Pessoa. Mas afinal... O que é mesmo documentário? São Paulo: SENAC São Paulo, 2008.

STAM, Robert. Teoria e prática da adaptação: da fidelidade à intertextualidade. Ilha do Desterro, Florianópolis, n. 51. p. 19-53, jul./dez. 2006. 


\section{açãô midiática \\ Estudos em Comunicação, Sociedade e Cultura \\ № 8 I Ano 2014}

TAVARES, Denise. Fronteiras entre cinema e jornalismo. In: FORÚM NACIONAL DE PROFESSORES DE JORNALISMO, 8., 2005, Brasília. Anais... Brasília: FNPJ, 2005. Disponível em: <http://www.fnpj.org.br/downloads/denise(cinema-jornal)2005.pdf $>$. Acesso em: 23 de julho de 2010. 